IIASA RR-88-007. Reprinted from Climatic Change, 12 (3). pp. 245-263

\title{
CARBON DIOXIDE EMISSIONS IN A METHANE ECONOMY
}

\author{
JESSE H. AUSUBEL
}

National Academy of Engineering. Washington, D.C.

ARNULF GRÜBLER

International Institute for Applied Systems Analysis, Laxenburg, Austria

and

NEBOJSA NAKICENOVIC

International Institute for Applied Systems Analysis, Laxenburg, Austria

\begin{abstract}
Increasing reliance on natural gas (methane) to meet global energy demands holds implications for atmospheric $\mathrm{CO}_{2}$ concentrations. Analysis of these implications is presented, based on a logistic substitution model viewing energy technologies like biological species invading an econiche and substituting in case of superiority for existing species. This model suggests gas will become the dominant energy source and remain so for 50 years, peaking near 70 percent of world supply. Two scenarios of energy demand are explored, one holding per capita consumption at current levels, the second raising the global average in the year 2100 to the current U.S. level. In the first ('efficiency') scenario concentrations peak about $450 \mathrm{ppm}$, while in the second ('long wave') they near $600 \mathrm{ppm}$. Although projected $\mathrm{CO}_{2}$ concentrations in a 'methane economy' are low in relation to other scenarios, the projections confirm that global climate warming is likely to be a major planetary concern throughout the twenty-first century. A second finding is that data on past growth of world per capita energy consumption group neatly into two pulses consistent with longwave theories in economics.
\end{abstract}

Future anthropogenic emissions of carbon dioxide, the principal gas expected to contribute to warming and other changes in the global climate, have been calculated by a variety of increasingly sophisticated methods (Ausubel and Nordhaus, 1983; Nordhaus and Yohe, 1983; Edmonds et al., 1985). Numerous specific scenarios have been explored, including those relating to 'dirty' fossil fuels such as oil shale (MacDonald, 1982), greatly enhanced energy conservation (Lovins et al., 1982; Goldemberg et al., 1985), and introduction of nuclear and alternative energy technologies (Rose et al., 1983). Perhaps the only future energy path not to be explored in detail in connection with $\mathrm{CO}_{2}$ emission is - natural gas (methane). In this paper, we present an analysis of the implications for atmospheric $\mathrm{CO}_{2}$ concentrations of increasing reliance on combustion of natural gas.

A natural gas scenario is interesting for several reasons. First, if the historical succession of energy sources continues its pattern, there is a strong likelihood that gas will in fact become the globally preeminent fuel (Grübler and Nakicenovic, 1987). New markets for natural gas appear to be opening in electricity 
generation and in transportation, for example as feedstock for methanol to be used as automotive fuel. Second, natural gas is more desirable than other carbon fuels with respect to environment. Gas, as we will show, is relatively unimposing with respect to $\mathrm{CO}_{2}$ emissions and is also highly desirable in regard to the question of acid rain, as it creates almost no sulfur emissions. Third, recent drilling results suggest that gas resources may be much more abundant than is widely believed (Gold, 1985). Hefner (1984) provides a portrait of economic, geopolitical, and other benefits from a worldwide shift to natural gas.

We limit our consideration to naturally occurring deposits of methane. Methane produced by gasifying coal, for example, is not considered; such synthetic fuels would in almost all cases incur a substantial energy penalty in their production and thus lack the advantages of natural gas from the point of view of moderating the $\mathrm{CO}_{2}$ burden on the atmosphere.

We do not address the question of emissions of greenhouse gases other than $\mathrm{CO}_{2}$, for example, chlorofluorocarbons and nitrous oxide; it has been conjectured that the cumulative effect of these and other trace gases may rival $\mathrm{CO}_{2}$ in significance for climate warming (Dickinson and Cicerone, 1986). Indeed, methane itself is a greenhouse gas and has been increasing in the atmosphere (Bolle et al., 1986; Thompson and Cicerone, 1986). Methane is a natural constituent of air, arising from many biological processes, and seeping out of the earth as well. Recent increase in concentration of atmospheric methane is usually attributed to expansion in the number of farm animals and rice production. However, use of methane channeled into the energy system for fuel might also contribute to growth of methane in the air. For example, some amounts of methane are released into the atmosphere during the gas extraction process. Increase in atmospheric methane may also be caused in part by rising levels of carbon monoxide from combustion of hydrocarbons; $\mathrm{CO}$ competes for the hydroxyl radicals that remove methane from the air. It may be important to estimate such effects of vastly increased use of methane on the atmosphere and to explore the implications for atmospheric methane of verification of the theories of abiogenic methane described below. The latter might help explain aspects of the atmospheric methane record that have puzzled researchers.

The method for projection that we adopt is explicitly one of extrapolation. Unlike most extrapolations in energy forecasting, which often are based on only the very recent behavior of the energy system, we extrapolate from the largest continuous data base on primary energy use, going back to 1860 . We agree with Plutarch that history repeats itself.

Our basic hypotheses, verified by observation, are (1) that technologies behave like biological species invading an ecological niche, substituting - in case they are better fit for survival - for the existing species and (2) that the sources we use to satisfy energy demand - wood, oil, coal, gas, and nuclear and solar technologies - may be regarded as species competing for an ecological niche. This Darwinian view of technologies leads to the use of a 'market penetration' or 'logistic substi- 


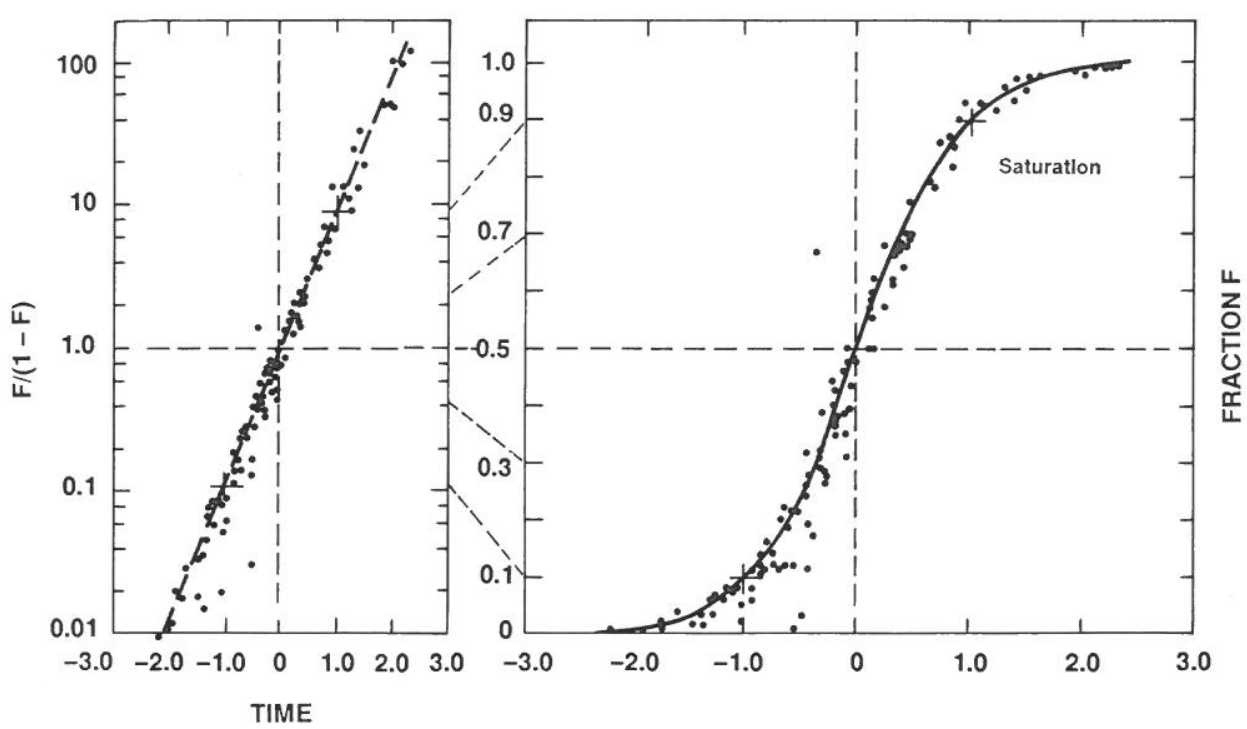

Fig. 1. Life cycle in the introduction of 17 different innovations (adapted from Fisher and Pry, 1971). New technologies (including primary energy carriers) penetrate a market following a characteristic $\mathrm{S}$-shaped pattern. The figure shows the introduction of 17 different innovations (electric steel, synthetic fibers, etc.) described by the market share (F) the new technology holds in the market. In a simple case there are just two competing technologies: the old one being replaced (not plotted in the figure) and the new (superior) technology progressively gaining market share. The development of market share over time of a new technology can be described by a logistic function. This curve can be converted to a linear form. In plotting the ratio of the market share $(F)$ a new technology has acquired over the market share left to be acquired $(1-F)$ in logarithmic scale (i.e., $\log (F /(1-F))$, one transforms the logistic substitution curve into a straight line, which is better suited for optical inspection of the introduction and saturation phase of the substitution process.

tution' model. Figure 1 shows on the basis of the introduction of 17 different innovations (Fisher and Pry, 1971) that after a technology or product grabs a few percent of the market, it typically grows according to a path calculated by a simple logistic equation. Figure 2 shows the good fit resulting when the logistic substitution model is applied to historical energy data (Marchetti and Nakicenovic, 1979). The apparent fight for survival among energy technologies is as steady and regular as it is for hundreds of other examples of multispecies competition explored by many authors. To our knowledge no other energy model performs as well in reproducing the past behavior of the energy system over the long term.

Methodological and statistical features of describing technological growth and substitution processes by logistic functions and the techniques we employ are discussed in Nakicenovic (1988) and Grübler, Nakicenovic, and Posch (1987). Statistical problems of estimating the parameters of a logistic function from empirical data are sometimes substantial. In brief, the problem is to estimate three parameters with the following physical interpretations: one denoting rate of growth, a second its location in time (a parameter that shifts the function in 


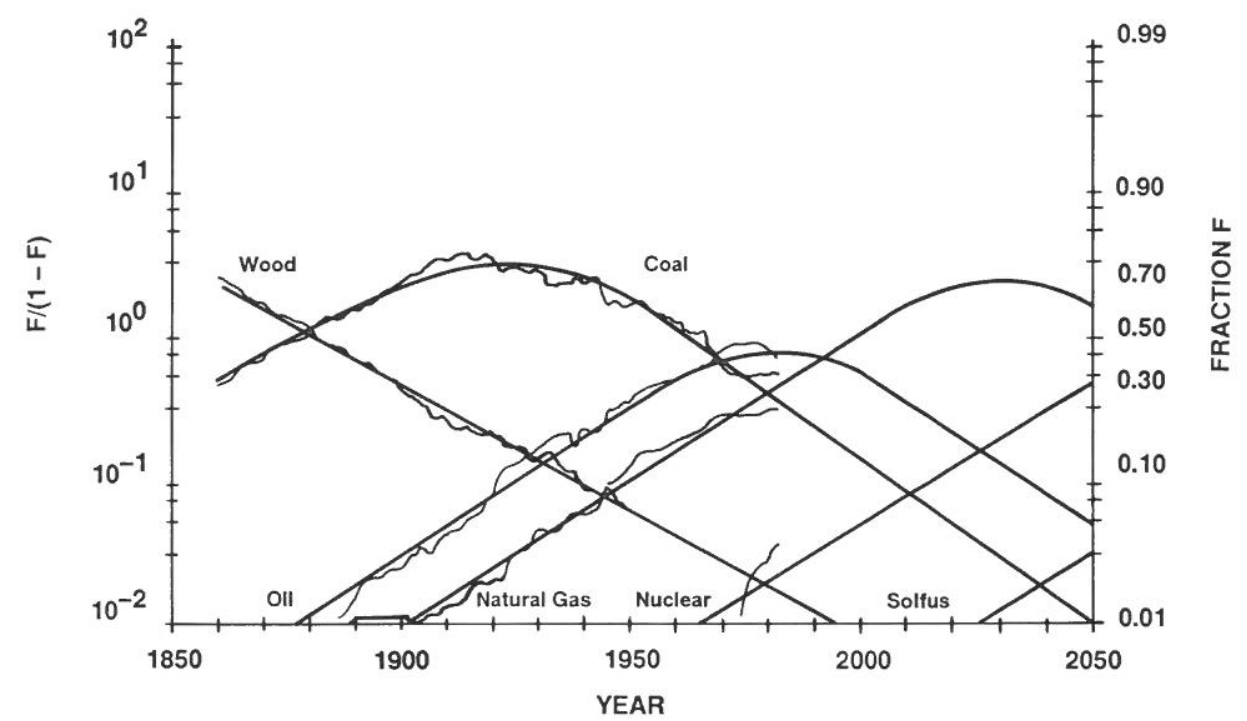

Fig. 2. World primary energy substitution. Smooth lines represent model calculations, and jagged lines are historical data. 'Solfus' is a term employed to describe a major new energy technology, for example solar or fusion (Marchetti and Nakicenovic, 1979; Grübler and Nakicenovic, 1987).

time but does not affect its shape), and finally the asymptote that bounds the function and therefore specifies the level at which the growth process saturates. In the case of technological substitution this asymptote parameter is known (maximum penetration achievable: $100 \%$ market share). Non-linear least square regression is used to estimate the unknown parameters of the function from the empirical observations. Alternative estimation algorithms are used to test sensitivity of estimated values of the parameters to different assumptions about errors and weighting of observations and select a preferred description.

Estimation of uncertainty ranges is based on a Monte Carlo simulation approach developed by Debecker and Modis (1986). As a rule of thumb, their results indicate that uncertainty of the saturation level will be less than $20 \%$ with a $95 \%$ confidence level, provided at least half of the data are available (i.e., data up to the inflection point of the process) with precision better than $10 \%$. Nakicenovic (1988) presents estimated parameter values, correlation coefficients, and uncertainty ranges for the energy substitution process described in this paper; the correlation coefficients for wood, coal, oil, and natural gas range between 0.96 and 0.99 . We have not yet performed sensitivity analyses of what would happen to emissions under a range of reasonable model applications; in this first effort we follow through only on one best fit case.

The market penetration model suggests that gas will soon become the dominant primary energy source and remain so for 50 or more years, peaking at close to $70 \%$ of world primary energy supply. If no newer technology were to challenge the technology invading a particular market, the new technology 
would approach $100 \%$ market share. This, however, is never the case in primary energy substitution, where any given energy carrier after a period of logistic market share growth starts to saturate and consequently loses market share to newer competitors along a logistic substitution path. We have assumed that gas will in turn be succeeded by noncarbon energy sources, first nuclear and then solar or fusion sources.

Indeed, public concern about climate change may lead to efforts to truncate the 'normal' market lifetime of methane (and other hydrocarbons). The difficulty in shortening the market penetration time of an energy technology lies in the extensiveness and cost of energy infrastructure; it may not be possible to build up or decommission systems on this physical and social scale in much less than 50 years.

Darmstater (1986) presents several useful critical views of the market penetration model. His central point is that the future may not be a smooth extension of past behavior. With respect to development of global energy demand, the two scenarios developed below take discontinuities explicitly into account and in their structure are at least compatible with observed long-term trends.

Having estimated or calculated a path of use of a particular primary energy source, it is a straightforward matter to calculate $\mathrm{CO}_{2}$ emissions. Table I presents the assumptions employed for this purpose. Note that natural gas emits only about $60 \%$ as much $\mathrm{CO}_{2}$ per unit energy as coal. Because the end-use of

TABLE I: Carbon emission factors

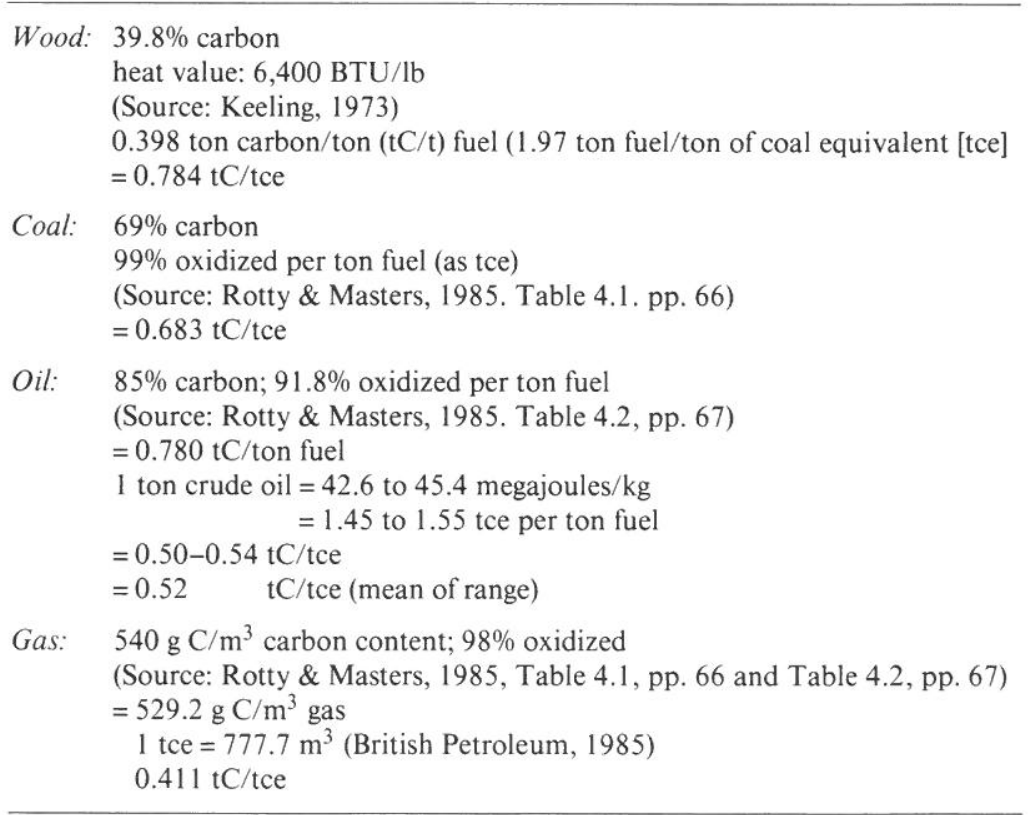


natural gas is more efficient than coal for many applications, the ratio for gas can be even more favorable.

There has been an intense debate between ecologists and oceanographers about what fraction of $\mathrm{CO}_{2}$ emissions is retained in the atmosphere (Trabalka, 1985; Bolin, 1986). Ecologists, who generally argue that the biosphere (deforestation) has been a large source of $\mathrm{CO}_{2}$ supplementing fossil fuel emissions, effectively hold that about $40 \%$ of emissions are retained in the atmosphere. Oceanographers, trusting records of diffusion of tritium and other elements and compounds in the oceans, generally are comfortable with a retention rate of about $60 \%$. We adopt a constant airborne fraction of $50 \%$. Readers can adjust this fraction upward or downward according to their own convictions. Predicting what the airborne fraction might be 100 years from now, when climate, land use patterns, and other significant factors will have altered considerably is one of the several fundamentally uncertain aspects of analysis of future greenhouse warming.

An interesting feature of the historically based approach used here is that it provides an estimate of the fraction of $\mathrm{CO}_{2}$ emissions due to the use of wood for fuel dating back to 1860 . Our estimate is about 24 billion tons of carbon. This compares with estimates of $90-180$ billion tons from all so-called biospheric sources (land-clearing, soils, etc.) in the period 1800-1980 (Trabalka, 1985) and 100-200 billion tons in the period 1860-1984 (Bolin, 1986). Our estimate challenges biospheric experts to account for the very large balance of the alleged biospheric emissions unrelated to energy use. Is it possible that such large amounts of wood not used for energy were burnt as part of agricultural land clearing?

The estimate of overall past $\mathrm{CO}_{2}$ emissions from oil, coal, and gas calculated by our method closely approximates the estimate made by Rotty and Masters (1985), who sought to conduct a careful accounting of fuel use year by year. Rotty and Masters estimate that emissions from so-called fossil fuels were about 170 billion tons between 1860 and 1982, whereas the market penetration model yields an estimate of about 164 billion tons.

We do not include marginal $\mathrm{CO}_{2}$ sources, such as the manufacture of cement; such omissions may mean that our method is biased low for future projections by $1-2 \%$, an amount one or two orders of magnitude lower than the overall uncertainty in the game. We also do not consider future $\mathrm{CO}_{2}$ emissions to the atmosphere from land-clearing, which seem unlikely to exceed the current probable range of $0-1$ billion tons of carbon emissions per year.

We examine two scenarios of future energy use, both based on extrapolation of the market penetration model to the year 2100 (Figure 3). Thus, shares of fuels in the two scenarios are identical. The question is what overall level of energy use the shares are applied to. Both scenarios we examine are population driven. We adopt the World Bank estimates ( $\mathrm{Vu}, 1985)$ of population growth, with population increasing from 5 billion in 1987 to 10.4 billion in 2100 . 


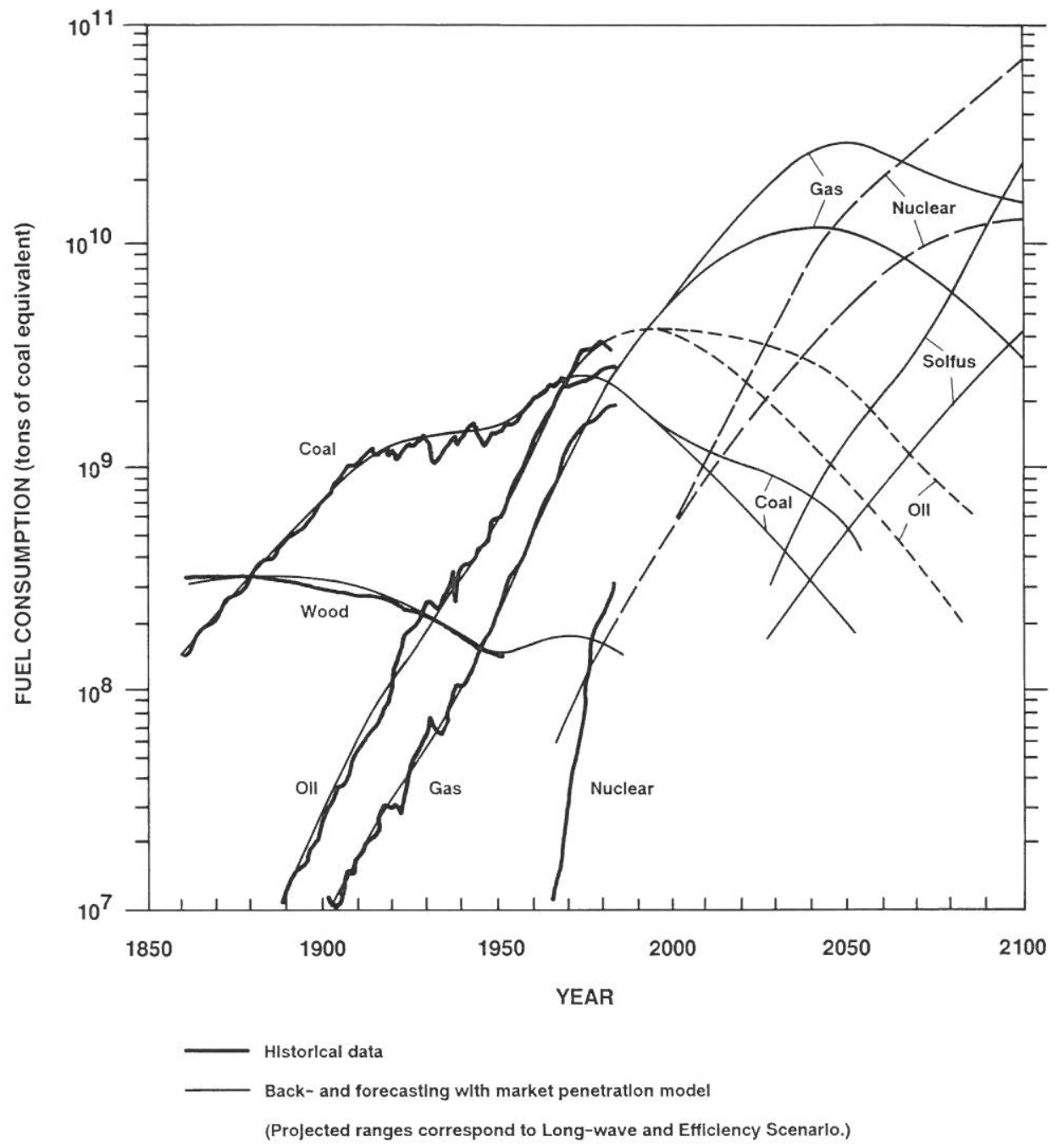

Fig. 3. Historical evolution of annual consumption of primary energy carriers at the world level and projections for two methane-intensive scenarios. (Note that in the model calculations we omit energy forms once they fall below $1 \%$ market share.)

One of our scenarios, which we call the 'efficiency' scenario, holds global annual average per capita energy consumption at 2 tons of coal equivalent (tce), the 1980 level. Under this scenario world energy consumption increases from currently less than 10 billion tons of coal equivalent (btce) in 1987 to about 21 btce in 2100 . With application of breakthroughs in conservation and efficiency, for example in superconductivity, this scenario would imply global development; otherwise, it may be regarded as a no-growth scenario. Table II shows the integrated fuel use in the scenario. Only some 55 btce of coal and some 185 btce of oil would be used in the future - roughly one-third the coal extracted so far in 
TABLE II: Integrated energy consumption 1988-2100, billion tons of coal equivalent (btce)

\begin{tabular}{lccccccc}
\hline & Total & Wood & Coal & Oil & Gas & Nuclear & Solfus \\
\hline $\begin{array}{l}1860-1987 \\
\text { Efficiency }\end{array}$ & 353 & 31 & 161 & 103 & 55 & 3 & 0 \\
$\begin{array}{l}\text { Scenario } \\
1988-2100\end{array}$ & 1930 & n.a. ${ }^{\mathrm{a}}$ & 55 & 185 & 915 & 665 & 110 \\
$\begin{array}{l}\text { Long-wave } \\
\text { Scenario } \\
1988-2100\end{array}$ & 5200 & n.a. ${ }^{\mathrm{a}}$ & 70 & 275 & 2140 & 2275 & 440 \\
\hline
\end{tabular}

a Not estimated, as energy consumption is $<1$ btce/year.

human history and about one and a half times the oil so far used. However, gas consumption would pass 900 btce, approximately 17 times as much as has been used so far.

The second scenario is based on the 'long-wave' theories of Kondratieff (1926, 1928) and Schumpeter (1939) and more recent theoretical and phenomenological work by Mensch (1979), Marchetti (1981), van Duijn (1983), Nakicenovic (1984), and Kleinknecht (1987). According to this theory, there have been three long swings of about 50 years each in economic development since the onset of the industrial revolution. Rather than continuous growth, long-wave theory supports the idea that growth comes in pulses stimulated by the clustered appearance of basic innovations, which lead to new products and whole new industries. Evidence from long time series supports these long-term fluctuations in economic development, but not unequivocally.

In Figure 4 we have grouped actual data on past growth of per capita energy consumption to show two pulses in world per capita energy consumption, dating back to 1860 . The existence of these pulses is a striking finding in itself and merits further research. We conjecture that each pulse reaches a kind of economic, socio-technical, and environmental feasibility limit for the leading energy source of the era, coal in the first case and oil in the second. The pulses, lasting 40-45 years, are followed by "depressions" in energy consumption. During such a depression, which in fact is characterized by change in dominant technical features of the economy, we observe oscillations in energy consumption between the levels delineated by the overlapping growth pulses. In each growth pulse, per capita energy consumption increases by approximately a factor of three. We have postulated two new pulses, centered 66 years after the preceding pulse, repeating historical experience.

Assuming that history continues to unfold as it has in the past, annual per capita energy use will increase in the third pulse from 2.0 tce to 6.0 tce around 2050. Another pulse would begin later in the twenty-first century, bringing average world annual per capita energy consumption to about 12 tce in 2100 . 


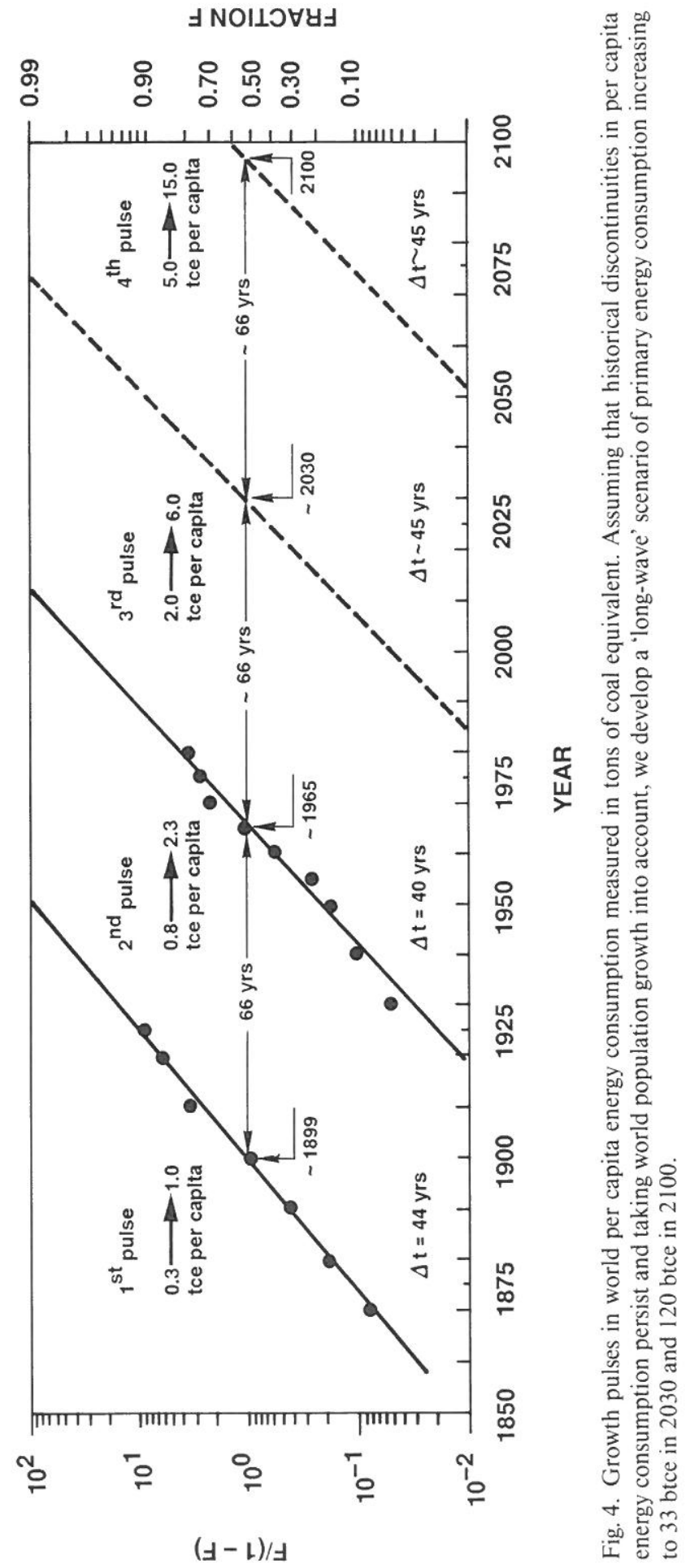




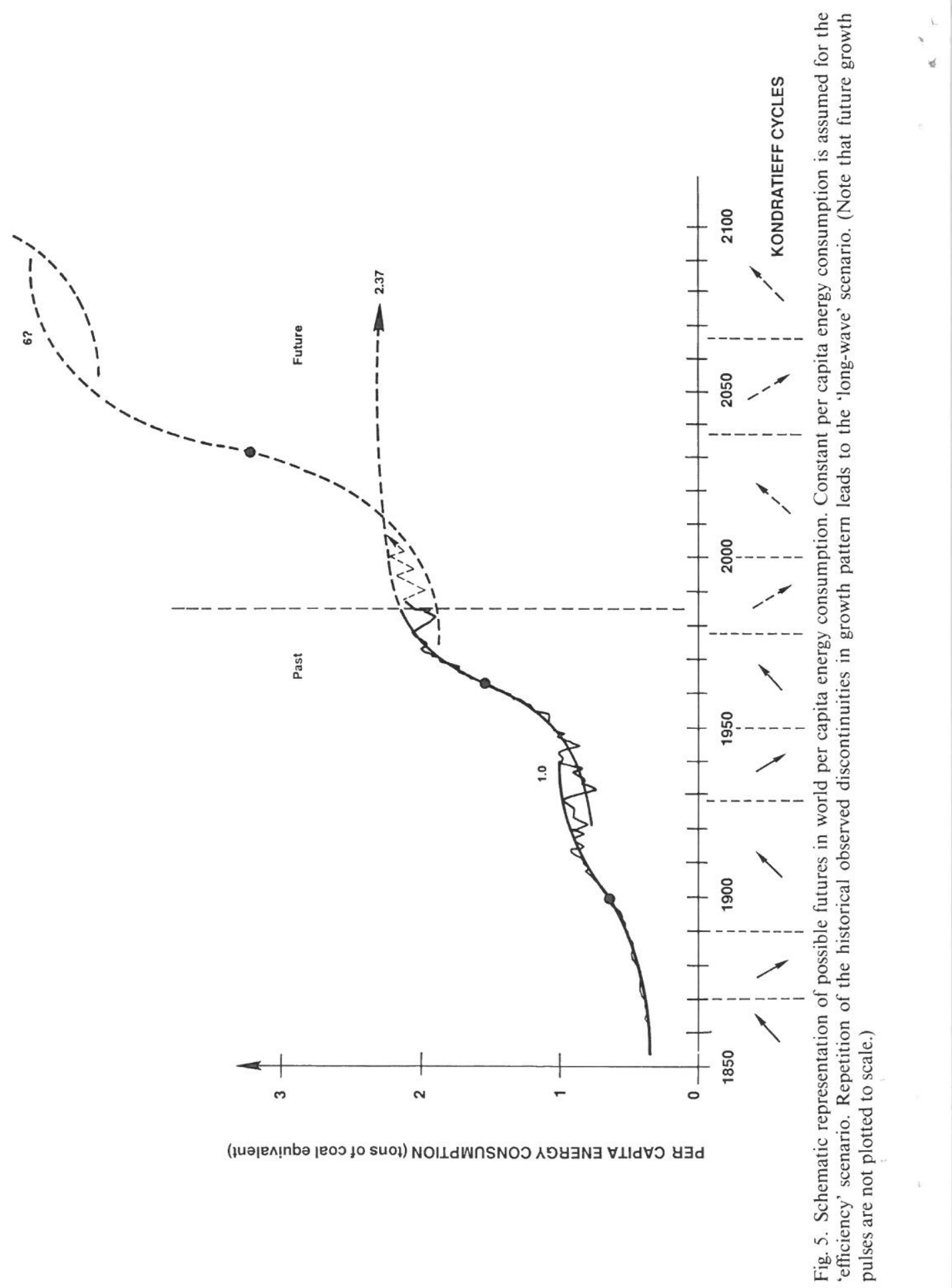


Current annual per capita energy consumption in the United States is about 12 tce. Thus, the long-wave scenario would bring the world average consumption to $50 \%$ of current U.S. consumption by the year 2050 and to current U.S. levels about 100 years from now. The inflection points of the pulses, indicating time of maximum growth rates in per capita energy consumption, occur in 2030 and 2100 , respectively. Figure 5 shows a conceptual representation of the long-wave scenario. This approach presents conservation and efficiency in a different light, dominant forces in one phase of a helical movement of the system. Stewart (1981) presents a similar long-term perspective on energy use, suggesting that end-use efficiency becomes a major factor in final demand as technologies mature, but is submerged in periods of upswing associated with clusters of new technologies. Figure 6 indicates the differing levels of energy use that the two scenarios result in.

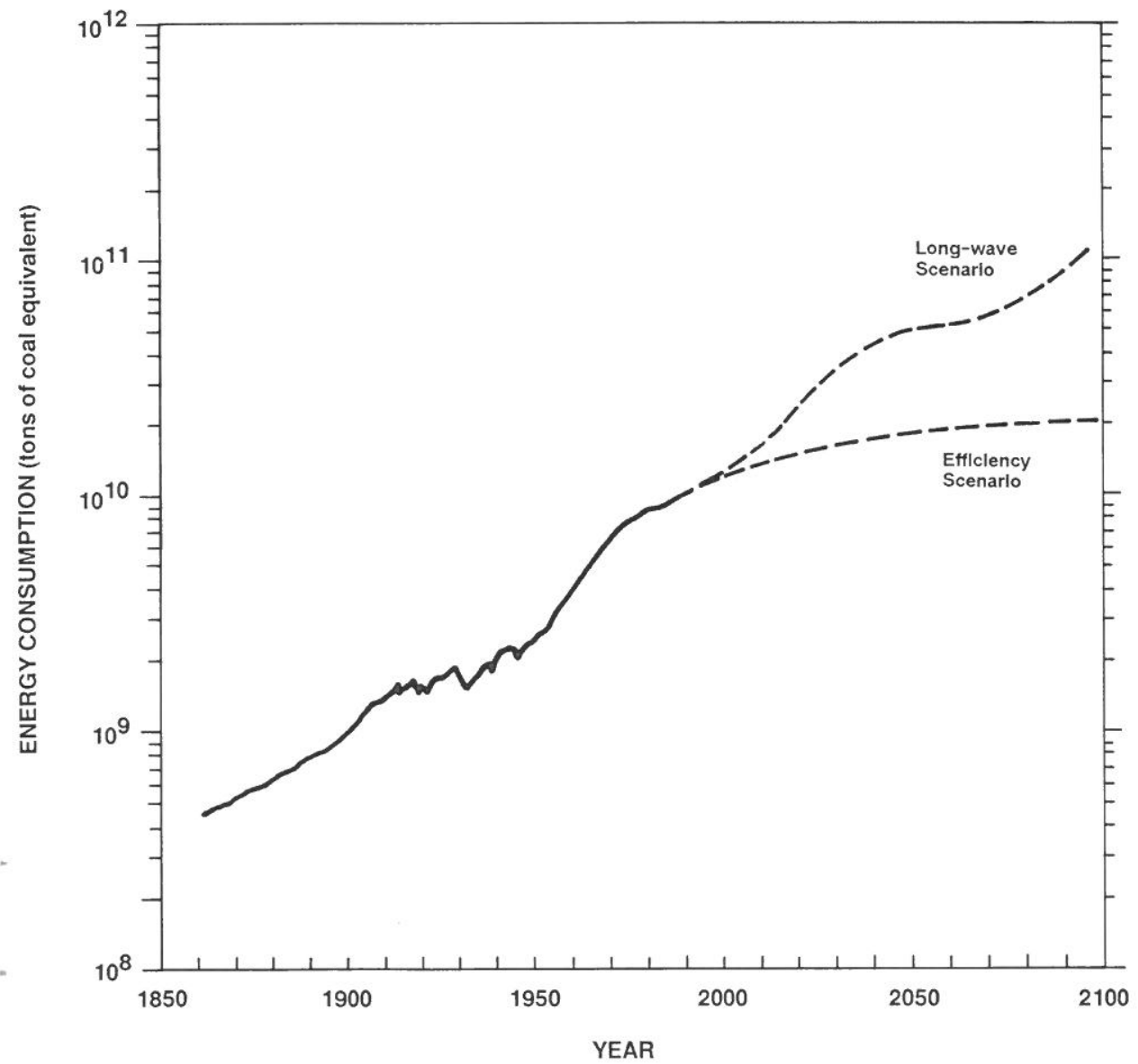

Fig. 6. Annual world primary energy consumption, historic and projected for long-wave and efficiency scenarios. 
TABLE III: Primary energy use and market shares for efficiency and long-wave scenarios (btce, rounded figures)

\begin{tabular}{lccccc}
\hline & & \multicolumn{3}{c}{ Efficiency scenario } & \multicolumn{2}{c}{ Long-wave scenario } \\
Year & 1986 & 2030 & 2100 & 2030 & 2100 \\
\hline Wood & $<1(1 \%)$ & $<1$ & $<1$ & $<1$ & $<1$ \\
Coal & $2(21 \%)$ & $<1$ & $<1$ & $1(3 \%)$ & $<1$ \\
Oil & $4(41 \%)$ & $2(11 \%)$ & $<1$ & $4(11 \%)$ & $<1$ \\
Gas & $3(34 \%)$ & $12(69 \%)$ & $3(14 \%)$ & $23(69 \%)$ & $16(14 \%)$ \\
Nuclear & $<1(3 \%)$ & $3(16 \%)$ & $13(63 \%)$ & $5(16 \%)$ & $77(63 \%)$ \\
Solfus & 0 & $<1$ & $5(23 \%)$ & $<1$ & $27(23 \%)$ \\
Total energy & & & & & \\
consumption & 10 & 17 & 21 & 33 & 120 \\
\hline
\end{tabular}

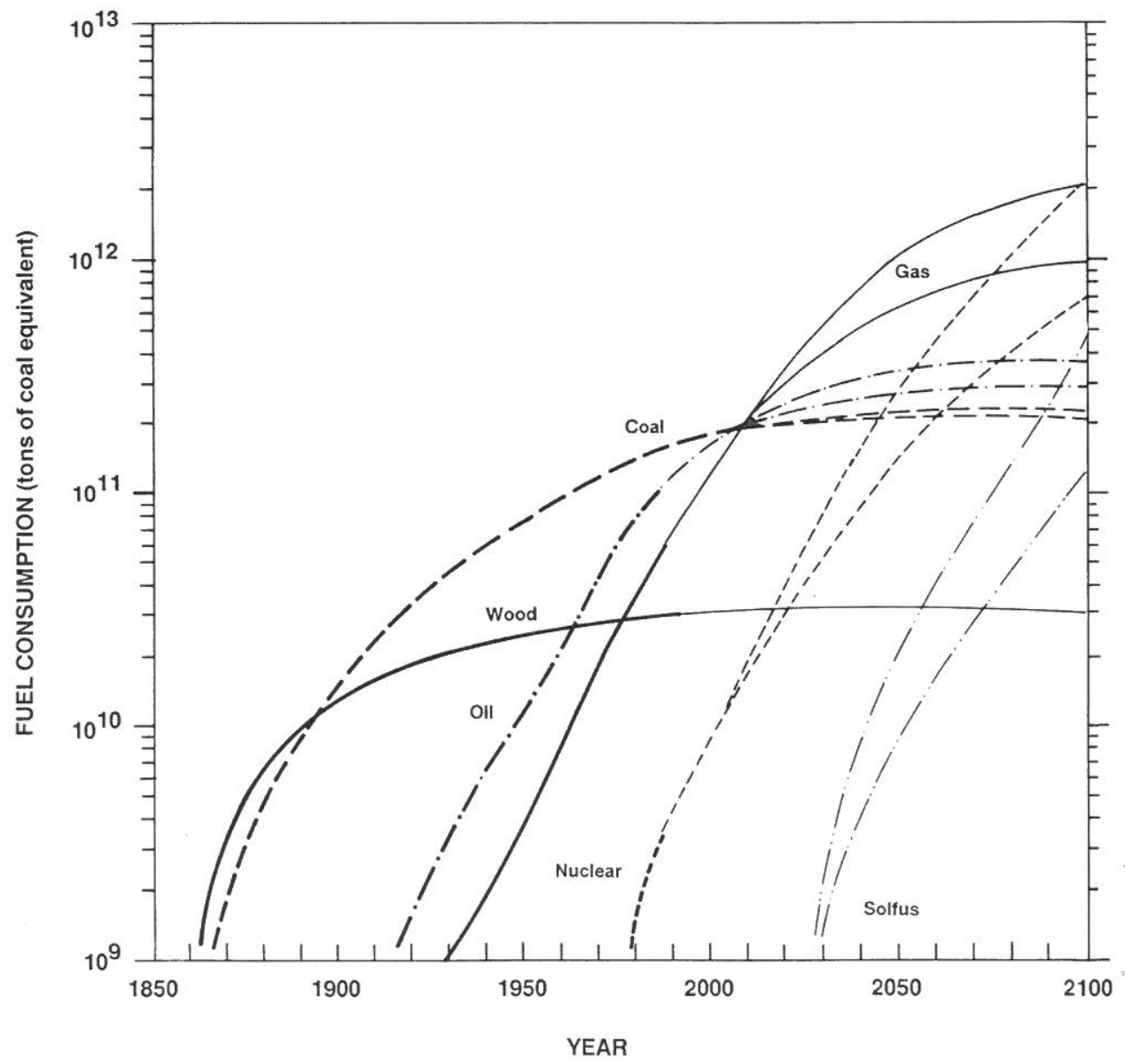

Fig. 7. Cumulative world primary fuel consumption projected for two methane-intensive scenarios. The range in the projections corresponds to the long-wave and efficiency scenarios. 
Table III shows current and projected energy use and shares for both the efficiency and the long-wave scenario in the year 2030, often used as a benchmark year in energy studies, and in the year 2100 . Though the 69 percent share for gas in 2030 is radically different from other energy scenarios, the energy use levels of 17 and 33 btce for 2030 are typical of 'low' and 'high' scenarios projected for this time frame (Häfele, 1981). The long-wave scenario leads to energy consumption in 2100 of 120 btce; this is higher consumption than almost all other energy scenarios. Integrated fuel use is shown in Table II and Figure 7.

Though consumption of 709 btce coal and 275 btce oil in the long-wave scenario is well within current estimates of resources, the use of 2140 btce of gas requires revision of traditional estimates of gas resources. The upper range of currently estimated ultimately recoverable resources of conventional gas is 11000 trillion cubic feet or about 400 btce. Our figure is thus about five times larger than common current estimates. If we apply Hanneman's (1986) estimate for the United States of the ratio of unconventional to conventional gas resources at the world level, total global gas resources would be about 4600 btce. This extension appears reasonable in light of the fact that geophysical exploration and characterization of resources have proceeded much further for the United States than for any other large sample of continental area.

Moreover, according to Linden (1986) it is now quite evident that accessible portions of the earth's crust contain a great deal more methane than liquid hydrocarbons. Natural gas is being found, and has repeatedly been found, in areas where such discoveries were supposed to be highly unlikely. Indeed, as Linden points out, the growing evidence of widespread and much greater abundance of methane in the earth's crust than is consistent with traditional geological theory has led an increasing number of researchers to reopen the question of the origin of terrestrial hydrocarbons and fossil fuels in general.

The abiogenic theory of methane formation developed by Gold $(1979,1985)$ and others holds that much of the carbon in the earth's crust is derived from outgassing of methane evolved from hydrocarbons trapped in the formation of the earth (in contrast to being 'fossil' remains of living organisms). Drilling in Sweden, the U.S.S.R., and elsewhere appears to provide support for the theory that a significant part of natural gas is a result of outgassing of primordial hydrocarbons from the mantle. Such a theory implies that vast reserves of gas might be found in deep faults and rifts and other areas previously ignored in energy exploration. It has been reported (New York Times, 22 March 1986) that drilling at a depth of almost 20000 feet in the Siljan Crater in Sweden may have tapped a large reservoir of primordial methane. However, prevailing opinion among geologists is certainly that recoverable resources of hydrocarbons are the result of abundant surface biology where cap rocks then sealed off large masses of organic sediments. Although the debate over the origins and amounts of 'fossil' fuels in the earth is certain to continue, the consumption of natural gas projected in the long-wave scenario is at least consistent with some geological 
theories and resource estimates. The high level of gas consumption in the longwave scenario could well involve price volatility at times of peak consumption and market share (circa 2030), as large investments are needed to convert resources into recoverable reserves.

Figure 8 presents the projected carbon emissions for the two scenarios. In the efficiency scenario, emissions stay roughly constant over the next 50 years, peaking only about 20 percent above current emissions at 6 billion tons of carbon (btC) in about the year 2025. In the long-wave scenario, emissions peak steeply at a level close to $15 \mathrm{btC}$ per year shortly before 2050. In the efficiency scenario, emissions are little more than 1 btC in the year 2100 , whereas in the long-wave scenario the emissions fall below $7 \mathrm{btC}$ in that year. We believe our two scenarios bracket virtually all reasonable scenarios of carbon emissions for the next 100 years in a gas-intensive economy.

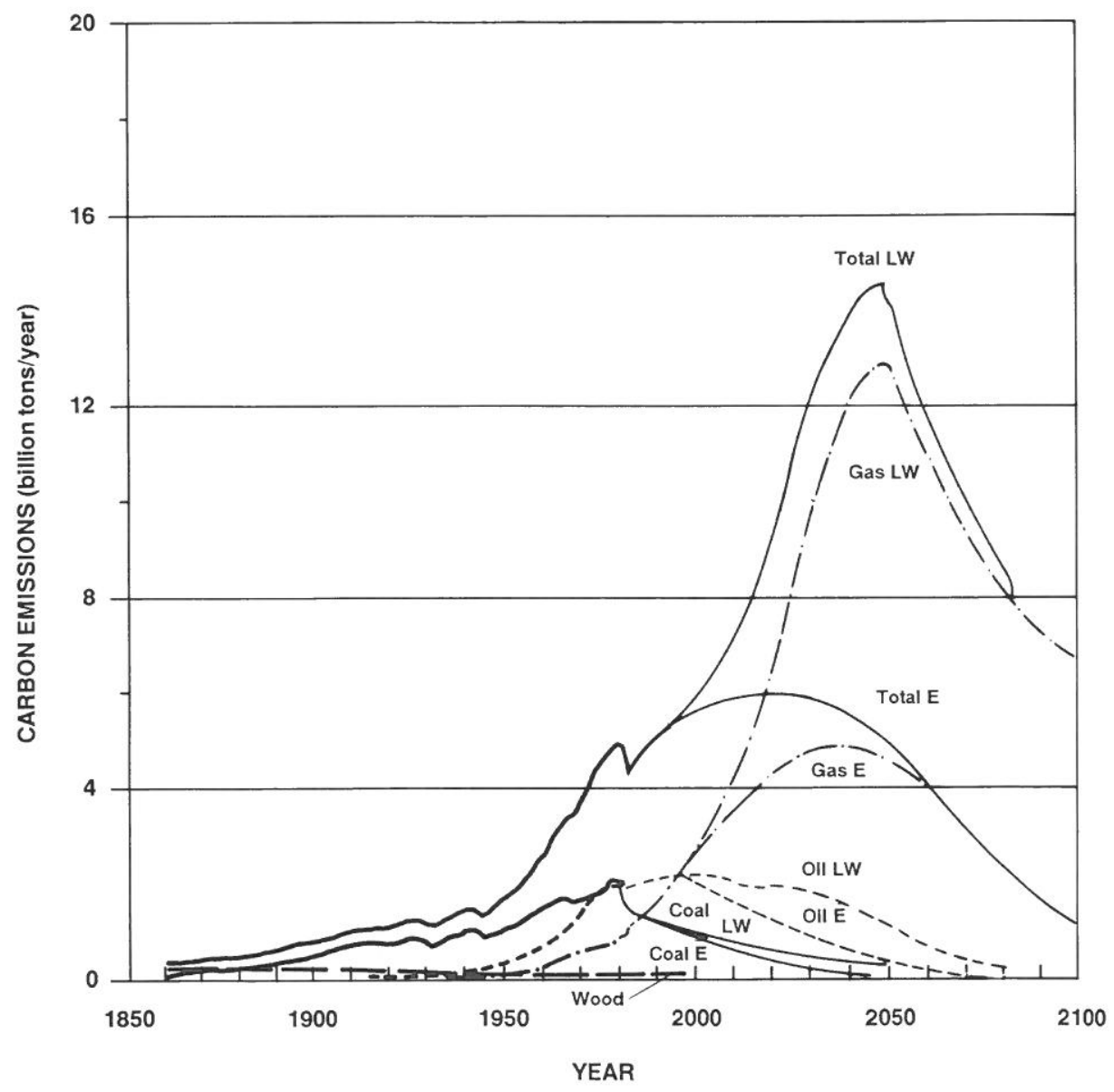

Fig. 8. Historic carbon emissions and projections for two methane-intensive scenarios. 
Figure 9 presents our estimates of future atmospheric $\mathrm{CO}_{2}$ concentrations. In the efficiency scenario, concentrations increase from today's level of about 350 parts per million (ppm) to $400 \mathrm{ppm}$ in about 2030 and $450 \mathrm{ppm}$ in 2075 . Shortly after this time, a decline would begin, had we employed a more sophisticated representation of the carbon cycle and the absorptive capacity of the oceans. In the long-wave scenario, concentrations reach $400 \mathrm{ppm}$ around $2020,450 \mathrm{ppm}$ in 2040 , and about $500 \mathrm{ppm}$ in 2060 , before leveling off at about $600 \mathrm{ppm}$ (the proverbial 'doubling' of the level used in models to simulate the recent behavior of the climate) in 2100 .

Our findings in this paper confirm that the issue of global climate warming is likely to be a major planetary concern throughout the twenty-first century, especially if non- $\mathrm{CO}_{2}$ greenhouse gases rival $\mathrm{CO}_{2}$ emissions. However, they also show that evolutionary development of the world energy system strictly consistent with the past 130 years leads to a range of estimates of future $\mathrm{CO}_{2}$

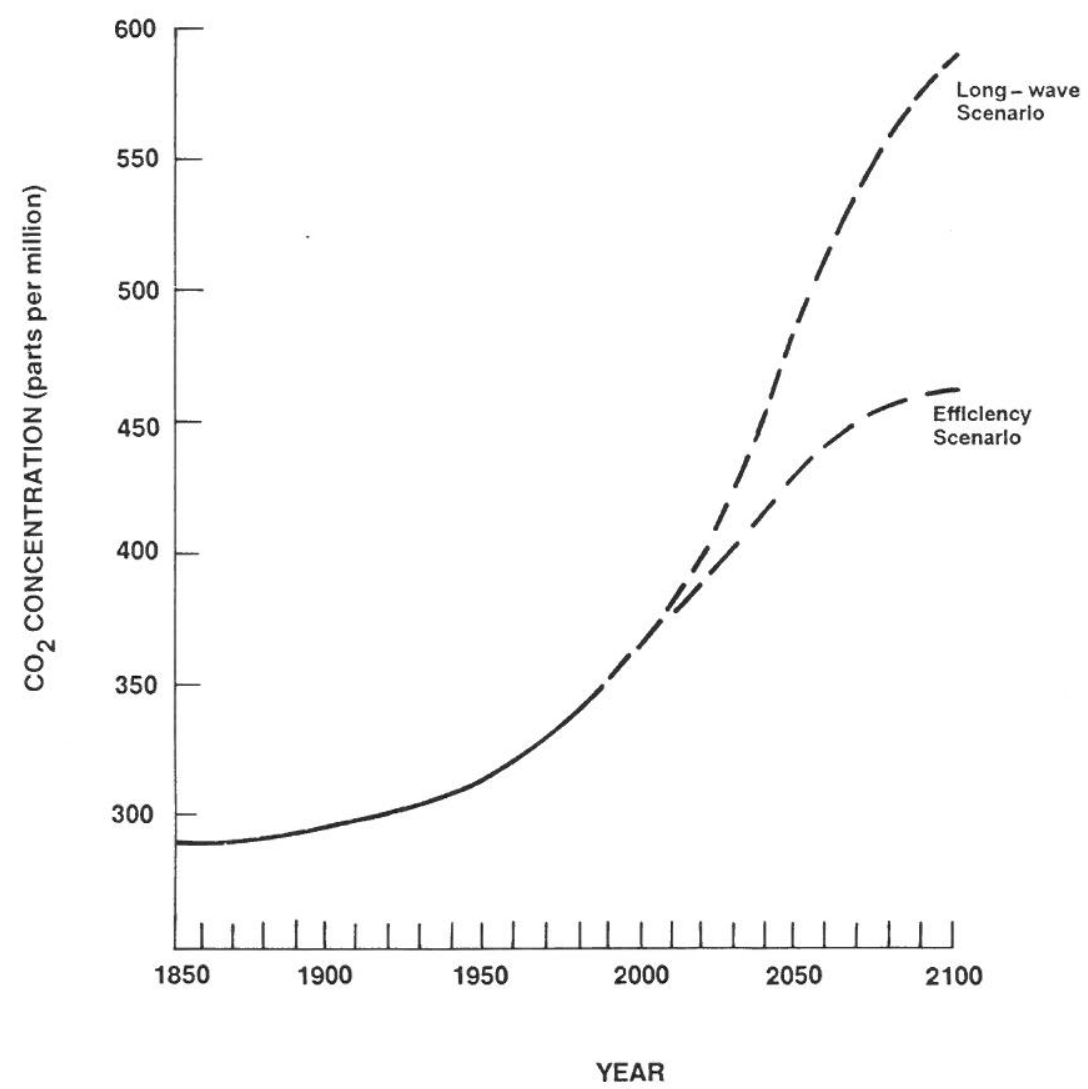

Fig. 9. Estimates of global atmospheric $\mathrm{CO}_{2}$ concentrations for two methane-intensive scenarios. Concentrations from 1860-1957 come from indirect measurements; those from 1958-1986 by direct measurement and those from 1987-2100 are calculated by the model. 


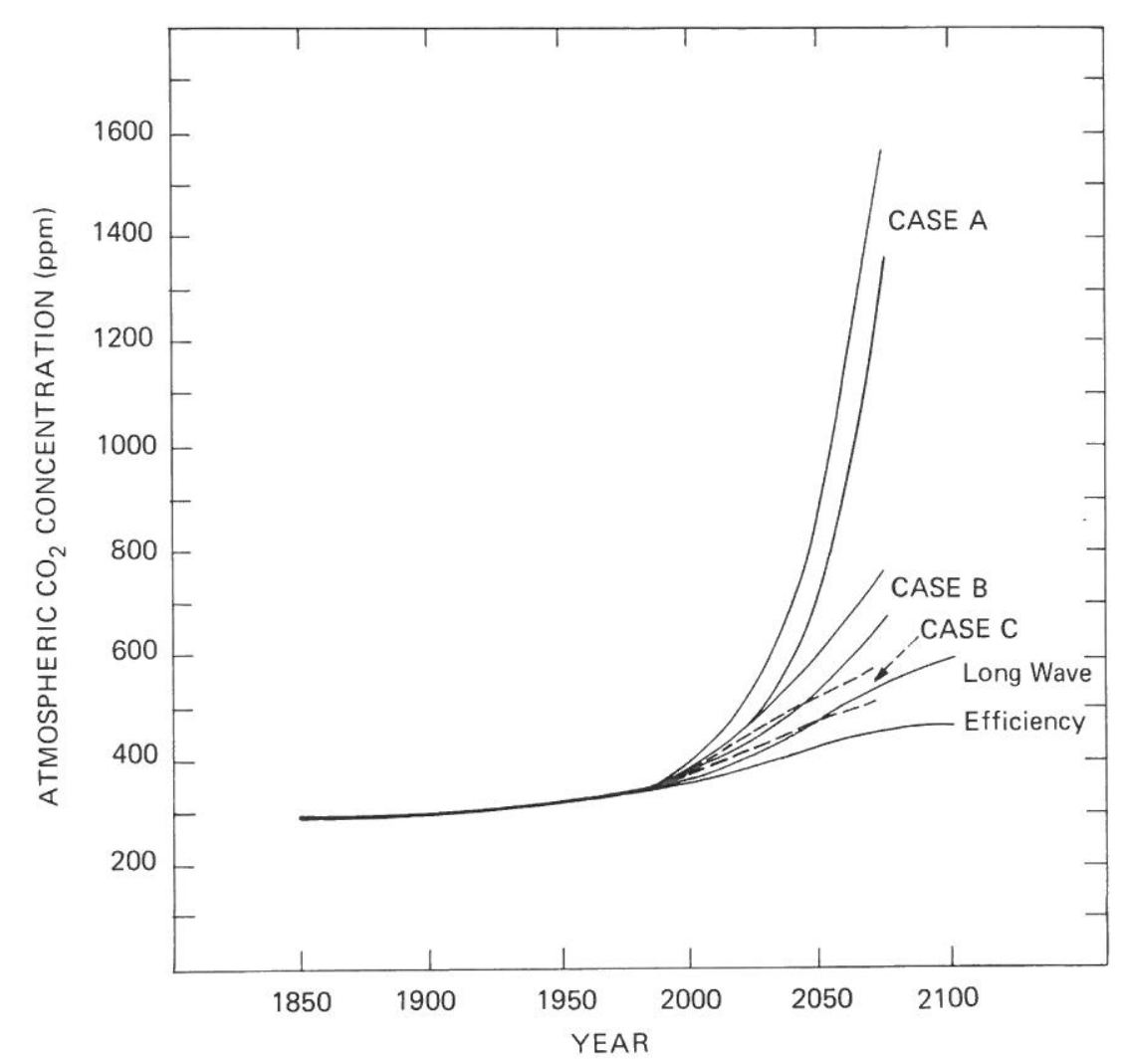

Fig. 10. Methane-intensive scenarios (long-wave and efficiency) contrasted with high, standard, and low reference projections (Cases A, B, C) prepared for the U.S. Department of Energy (DOE) (Trabalka, 1985, p. 276; based on Edmonds et al., 1985). Pairs of cases are calculated for high and low airborne fraction.

concentrations that are low compared to standard estimates (Figure 10). Nordhaus and Yohe (1983), for example, estimated that there is about a 1-in-20 chance that concentrations would be as low as $540 \mathrm{ppm}$ in 2100 and Edmonds et al. (1985) calculate their 'low' case (Case C in Figure 10) to be between 510 and $580 \mathrm{ppm}$ in 2075 .

The reasons for our relatively moderate estimates are obvious - gas emits less $\mathrm{CO}_{2}$ than other fossil fuels and we project that under the wing of gas, noncarbon energy sources (nuclear, solar, or others) will become significant by 2100 . We close by pointing out that we may be just midway through the hydrocarbon era and that the long-term evolution of the world energy system has been toward an increasing ratio of hydrogen to carbon (Figure 11). From this perspective, methane is the transitional hydrocarbon, and the great energy breakthrough that we must look, hope, and work for during the next decades is the production of hydrogen by means not involving carbon fuels. 


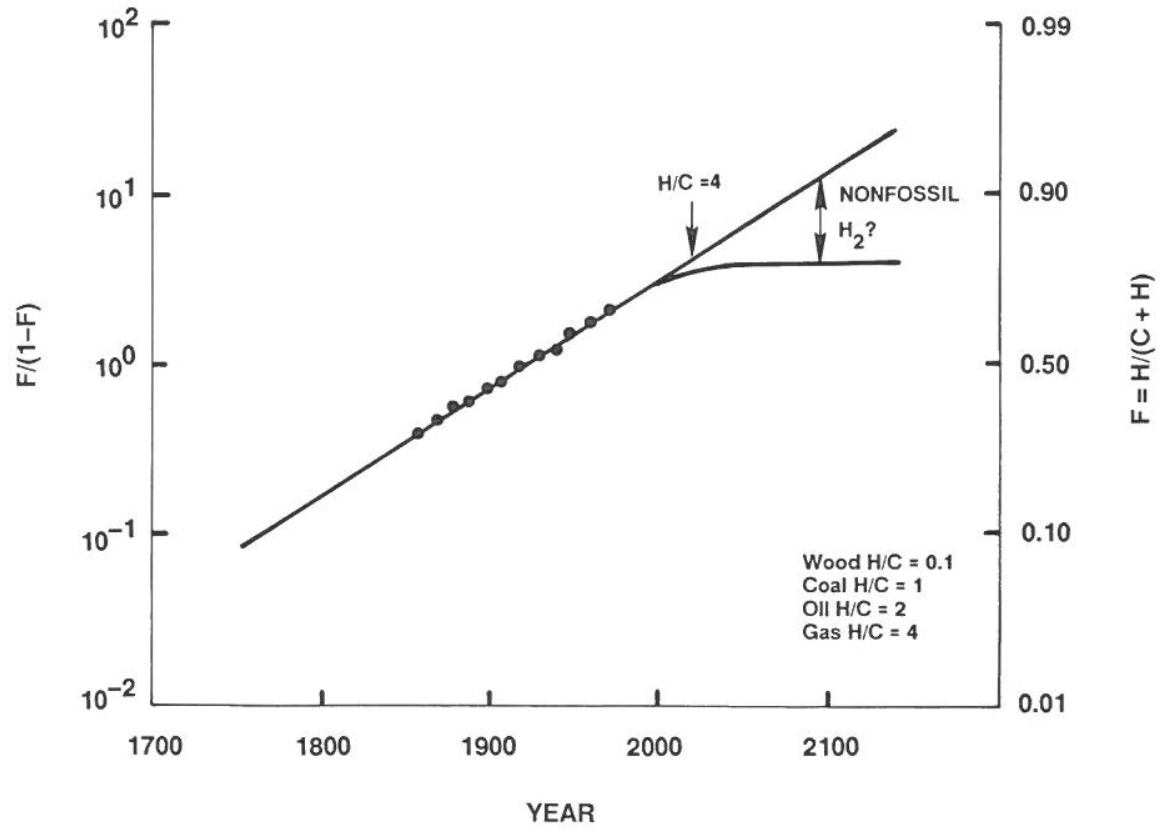

Fig. 11. Evolution of the ratio of hydrogen $(\mathrm{H})$ to carbon $(\mathrm{C})$ in the world fuel mix. The figure for wood refers to dry wood suitable for energy generation. If the progression is to continue beyond methane, production of large amounts of hydrogen fuel without fossil energy is required. See Marchetti, 1985.

\section{References}

Ausubel, J. H. and Nordhaus, W. D.: 1983, 'A Review of Estimates of Future Carbon Dioxide Emissions', in Changing Climate: Report of the Carbon Dioxide Assessment Committee, National Academy Press, Washington, D.C., pp. 153-185.

Bolin, B.: 1986, 'How Much $\mathrm{CO}_{2}$ Will Remain in the Atmosphere?' in B. Bolin, B. R. Doos, and J. Jaeger (eds.), The Greenhouse Effect, Climatic Change, and Ecosystems: A Synthesis of Present Knowledge, Wiley, Chichester, pp. 93-156.

Bolle, H. J., Seiler, W., and Bolin, B.: 1986, 'Other Greenhouse Gases', in B. Bolin, B. R. Doos, and J. Jaeger, (eds.), The Greenhouse Effect, Climatic Change, and Ecosystems: A Synthesis of Present Knowledge, Wiley, Chichester, pp. 157-203.

British Petroleum, 1985, BP Statistical Review of World Energy, British Petroleum Company, London.

Darmstater, J.: 1986, 'Energy Patterns - In Retrospect and Prospect', in W. C. Clark and R. E. Munn, Sustainable Development of the Biosphere, Cambridge University Press, Cambridge, England.

Debecker, A. and Modis, T. (Digital Equipment Corporation, Geneva, Switzerland): 1986, 'Determination of the Uncertainties in S-curve Logistic Fits', Paper submitted to the Sixth International Symposium on Forecasting, Paris, June 15-18, 1986.

Dickinson, R. E. and Cicerone, R. J.: 1986, 'Future Global Warming From Atmospheric Trace Gases', Nature 319, 109-115.

Duijn, J. J. van: 1983, The Long Wave in Economic Life, George Allen and Unwin, London.

Edmonds, J. A., Reilly, J. M., Gardner, R. H., and Brenkert, A.: 1985, Uncertainty in Future Global Energy Use and Fossil Fuel $\mathrm{CO}_{2}$ Emissions 1975 to 2075, Institute for Energy Analysis, Oak Ridge, Tenn. 
Fisher, J. C. and Pry, R. H.: 1971, 'A Simple Substitution Model of Technological Change', Technological Forecasting and Social Change 3, 75-88.

Gold, T.: 1979, 'Terrestrial Sources of Carbon and Earthquake Outgassing', Journal of Petroleum Geology 1 (3), 3-19.

Gold, T.: 1985, 'The Origin of Natural Gas and Petroleum, and the Prognosis for Future Supplies', Annual Review of Energy 10, 53-88.

Goldemberg, J., Johansson, T. B., Reddy, A. K. N., and Williams, R. H. 1985, 'An End-Use Oriented Global Energy Strategy', Annual Review of Energy 10, 613-688.

Grübler, A. and Nakicenovic, N.: 1987, 'The Dynamic Evolution of Methane Technologies', International Institute for Applied Systems Analysis, Laxenburg, Austria.

Grübler, A., Nakicenovic, N., and Posch, M.: 1987, 'Algorithms and Software Package for Estimating S-shaped Curves', International Institute for Applied Systems Analysis, Laxenburg, Austria.

Häfele, W. (Program Leader): 1981, Energy in a Finite World, Ballinger, Cambridge.

Hanneman, R. E.: 1986, ‘Methane Technology: A Technical Survey', Paper presented to the IIASA Task Force Meeting on the Methane Age, Sopron, Hungary, May 1986.

Hefner, R. H., III: 1984, 'Natural Gas - The Politically and Environmentally Benign Least-Cost Energy for Successful 21 st Century Economies, The Energy Path to a Better World', Paper presented to the First International Conference on Shallow Oil and Gas Resources, GHK Company, Oklahoma City, Okla., July 1984.

Keeling, C. D.: 1973, 'Industrial Production of Carbon Dioxide from Fossil Fuels and Limestones', Tellus 28, 174-198.

Kleinknecht, A.: 1987, Innovation Patterns in Crisis and Prosperity, Macmillan, London.

Kondratieff, N. D.: 1926, 'Die langen Wellen der Konjunktur', Archiv für Sozialwissenschaft und Sozialpolitik, Band 56, Tübingen, F.R.G.

Kondratieff, N. D.: 1928, 'Die Preisdynamik der industriellen und landwirtschaftlichen Waren', Archiv für Sozialwissenschaft und Sozialpolitik, Band 60, Tübingen, F.R.G.

Linden, H. R.: 1986, 'The Case for a Methane Intensive Economy', Gas Research Institute, Chicago, I11.

Lovins, A. B., Lovins, L. H., Krause, F., and Bach, W.: 1982, Least Cost Energy: Solving the $\mathrm{CO}_{2}$ Problem, Brick House Publishing, Cambridge, Mass.

MacDonald, G. J. (ed.): 1982, The Long-Term Impacts of Increasing Atmospheric Carbon Dioxide Levels, Ballinger, Cambridge, Mass.

Marchetti, C.: 1985, 'Nuclear Plants and Nuclear Niches', Nuclear Science and Engineering 90, $521-526$

Marchetti, C.: 1983, 'Recession 1983: Ten More Years to Go', WP-83-85, International Institute for Applied Systems Analysis, Laxenburg, Austria.

Marchetti, C.: 1981, 'Society as a Learning System-Discovery, Invention and Innovation Cycles Revisited', RR-81-29, International Institute for Applied Systems Analysis, Laxenburg, Austria.

Marchetti, C. and Nakicenovic, N.: 1979, 'The Dynamics of Energy Systems and the Logistic Substitution Model', RR-79-13, International Institute for Applied Systems Analysis, Laxenburg, Austria.

Mensch, G.: 1979, Stalemate in Technology, Ballinger, Cambridge, Mass.

Nakicenovic, N.: 1988, 'Dynamics and Replacement of U.S. Transport Infrastructures', in Cities and Their Vital Systems, National Academy Press, Washington, D.C.

Nakicenovic, N.: 1984, Growth to Limits, Long Waves and the Dynamics of Technology, University of Vienna, Austria.

Nordhaus, W. D. and Yohe, G.: 1983, 'Future Carbon Dioxide Emissions From Fossil Fuels', in Changing Climate: Report of the Carbon Dioxide Assessment Committee, National Research Council, National Academy Press, Washington, D.C., pp. 87-153.

Rose, D., Miller, M., and Agnew, C.: 1983, 'Global Energy Futures and $\mathrm{CO}_{2}$ Induced Climate Change', MIT Energy Laboratory 83-015, Massachusetts Institute of Technology, Cambridge, Mass.

Rotty, R. M. and Masters, C. D.: 1985, 'Carbon Dioxide From Fossil Fuel Combustion: Trends, Resources, and Technological Implications', in J. R. Trabalka (ed.), Atmospheric Carbon Dioxide and the Global Carbon Cycle, Department of Energy ER-0239, Washington, D.C. 
Schumpeter, J. A.: 1939, Business Cycles: A Theoretical and Historical Analysis of the Capitalist Process, Volumes 1 \& 2, McGraw-Hill, New York.

Stewart, H. B.: 1981, Transitional Energy Policy 1980-2030: Alternative Nuclear Technologies, Pergamon, Oxford.

Thompson, A. M. and Cicerone, R. J.: 1986, 'Possible Perturbations to Atmospheric CO, $\mathrm{CH}_{4}$, and OH', Journal of Geophysical Research 91, 10853-10864.

Trabalka, J. R. (ed.): 1985, Atmospheric Carbon Dioxide and the Global Carbon Cycle, Department of Energy ER-0239, Washington, D.C.

Vu, M. T.: 1985, World Population Projection 1985, Johns Hopkins University Press, Baltimore.

(Received 1 September, 1987; in revised form 21 December, 1987) 
